Relations industrielles

Industrial Relations

\title{
Industrial and Labor Relations Terms: A Glossary, by Robert E. Doherty, ILR Bulletin no 44, Fourth Edition, Ithaca, New York State School of Industrial and Labor Relations, Cornell University, 1979, 40 pp.
}

\section{Gérard Dion}

Volume 35, numéro 1, 1980

URI : https://id.erudit.org/iderudit/029053ar

DOI : https://doi.org/10.7202/029053ar

Aller au sommaire du numéro

Éditeur(s)

Département des relations industrielles de l'Université Laval

ISSN

0034-379X (imprimé)

1703-8138 (numérique)

Découvrir la revue

Citer ce compte rendu

Dion, G. (1980). Compte rendu de [Industrial and Labor Relations Terms: A Glossary, by Robert E. Doherty, ILR Bulletin no 44, Fourth Edition, Ithaca, New York State School of Industrial and Labor Relations, Cornell University, 1979, 40 pp.] Relations industrielles / Industrial Relations, 35(1), 173-173.

https://doi.org/10.7202/029053ar

Tous droits réservés (C Département des relations industrielles de l'Université Laval, 1980
Ce document est protégé par la loi sur le droit d'auteur. L'utilisation des services d'Érudit (y compris la reproduction) est assujettie à sa politique d'utilisation que vous pouvez consulter en ligne.

https://apropos.erudit.org/fr/usagers/politique-dutilisation/ 
surprend pas puisque c'est dans ces pays que les organisations syndicales approchent le plus le modèle de comportement économique proposé et que c'est surtout en Angleterre et aux États-Unis que les études théoriques et empiriques sur le sujet ont été produites. L'application du modèle à d'autres régimes de négociation collective, dans la mesure où elle évolue dans des systèmes de marchés et compte tenu d'un contexte international constituerait un nouveau champ d'exploration des plus intéressants. Pour le lecteur canadien, étant donné la similitude des régimes de relations industrielles qui l'entourent d'avec ceux des États-Unis et de l'Angleterre, le contenu du texte de Mulvey fait tout autant actualité.

Finalement, l'auteur, en tant qu'observateur assidu de l'économie anglaise et de la scène des relations industrielles de son pays, $y$ va de quelques conclusions et recommandations relativement aux effets économiques du syndicalisme en Angleterre. Selon l'auteur, l'une des principales constatations se dégageant de la partie deux, reste l'absence d'effets directs importants du syndicalisme sur l'inflation, le P.N.B. et la distribution du revenu entre travail et autres facteurs de production. Ce à quoi on semblerait plutôt assister en Angleterre toutefois, c'est à un protectionisme grandissant contre l'économie de marché, par exemple, les nationalisations d'industries et le haut niveau de prestations aux chômeurs dont une partie résulte de l'action syndicale dans les secteurs soumis a la concurrence et aux prix du marché. Ce faisant, il en résulte une inefficacité croissante de l'économie anglaise et un transfert de revenu entre payeurs de taxes et syndiqués et entre non-syndiqués et syndiqués. C'est pourquoi les politiques de contrôle de salaires sont inefficaces et devraient plutôt céder la place à des efforts pour revitaliser l'économie de marché, par exemple, en exigeant aux monopoles étatiques de se conformer à certains critères d'efficacité dans l'allocation de leurs ressources et en remplaçant l'assurancechômage publique par un régime universel de revenu annuel garanti. Ce sont là d'ailleurs des réflexions qui trouvent écho dans d'autres pays y compris au Canada et au Québec, bien que les résultats des études pilotes sur un régime tel l'impôt négatif sur le revenu avec revenu minimum garanti aux États-Unis, ne permettent pas de croire que leur application résoudrait de facto ces problèmes.

Jacques MERCIER

\section{Université Laval}

Industrial and Labor Relations Terms: $\mathbf{A}$ Glossary, by Robert E. Doherty, ILR Bulletin no. 44, Fourth Edition, Ithaca, New York State School of Industrial and Labor Relations, Cornell University, 1979, $40 \mathrm{pp}$.

On comprendra que ce n'est pas sans curiosité que j'ai examiné attentivement la quatrième édition de cette brochure publiée pour la première fois en 1962 par le professeur Doherty.

Elle comprend trois cents termes parmi les plus utilisés dans le domaine des relations du travail avec leur définition.

Par rapport aux éditions précédentes, l'auteur a laissé de côté un certain nombre d'expressions tombées en désuétude et a enrichi son texte d'expressions nouvelles pour tenir compte des nouveaux développements touchant la négociation collective, l'arbitrage, la législation et les décisions judiciaires etc. Nous en avons ainsi relevées près de quatre-vingt-dix. Par exemple, affirmative action, blue flue, burden of proof, demanddeficiency unemployment, duty of fair representation, front loaded, final arbitration, etc. Plusieurs définitions ont été reformulées avec plus de précision, complétées ou mises à jour.

Le seul regret que l'on peut signaler, c'est que ce glossaire ne soit pas plus considérable. Comme tel, cependant, il demeure un instrument utile à tous ceux qu'intéressent les relations du travail dans le contexte étatsunien.

Gérard Dion

\section{Université Laval}

